\title{
Socio-Economic Modernization and the "Crisis of Trust" in China: A Multi-level Analysis of General and Particular Trust
}

\section{H. Christoph Steinhardt ${ }^{1}$ (D) Jan Delhey ${ }^{2}$ (D)}

Accepted: 7 August 2020 / Published online: 19 August 2020

(c) The Author(s) 2020

\begin{abstract}
Theorists have long disagreed about the impact of socio-economic modernization on social trust. The pessimistic school asserts that modernization undermines the structural conditions for high levels of trust. The optimistic account argues that it delivers economic security and human empowerment and thereby enhances trust. Adapting these contrasting theories to the specific case of China, this article puts them to the test with survey data from the World Values Survey. Exploiting the condition of highly uneven levels of regional development, combined with common political institutions and a shared cultural heritage, the study conducts a multi-level analysis of survey data from over 1900 individuals and a wide range of regional statistics from 61 county-level units. While trust in family members and particular trust beyond the family are unaffected by levels of regional modernization, we find robust evidence to suggest that regional modernization is associated with substantially higher levels of general trust. The results further suggests that higher general trust in more developed regions does not lead to an enhanced conversion of particular into general trust. This indicates that general trust is nurtured through the contextual effect of residing in more modern social environments. Overall, these findings provide substantial support for modernization optimists and lend themselves to a reinterpretation of a widely discussed "trust crisis" in China, which to date is often interpreted according to the pessimistic view of modernization.
\end{abstract}

Keywords Trust · General trust $\cdot$ Particular trust $\cdot$ Modernization $\cdot$ Social capital $\cdot$ China $\cdot$ Asia

H. Christoph Steinhardt

hc.steinhardt@univie.ac.at

Jan Delhey

j.delhey@ovgu.de

1 Department of East Asian Studies, University of Vienna, Spitalgasse 2, Hof 2 (Campus), 1090 Vienna, Austria

2 Institute of Social Sciences, Otto von Guericke University Magdeburg, 39104 Magdeburg, Germany 


\section{The Issue: Modernization and Social Trust}

What is the impact of socio-economic modernization on social trust? Optimists claim that modernization boosts human empowerment through increasing collective resources, which puts people in a better position to trust their fellow citizens (Inglehart 1997; Inglehart and Welzel 2005). Pessimists, by contrast, argue that periods of rapid change and urbanization disrupt traditional social relations and norms, leading to an increasingly anonymous and distrustful society (Huntington 1973; Putnam 2000, 2007; Tönnies 1957; Wirth 1938).

In China, widely reported incidents of social apathy, uncivil behavior, cheating, or the extortion of Good Samaritans by those they assisted have initiated intense public debate on the state of social solidarity (Huang 2016; Yan 2009). Scholars and commentators largely follow the pessimistic narrative and often link an alleged "trust crisis" (xinren weiji) to the country's rapid development since the 1980s (China News Service 2020; Zhu 2012). A controversial social credit system is currently being developed by the authorities to resolve this confidence-deficit by creating reputation-based forms of trust (Dai 2018). However, systematic empirical evidence for both a breakdown of social trust and a possible link to modernization processes remains scarce. We therefore pose the question: is modernization in China associated with lower levels of social trust?

The case of China is uniquely suited for studying this association. The traditional social fabric in China is known for high levels of trust in family and close associates, combined with low trust in people outside these networks (Fei 1992; Fukuyama 1995; Weber 1968; see also Steinhardt 2012, pp. 439-441). Against this background, the country has experienced one of the most rapid socio-economic modernizations in human history. Within only three decades (1978-2007), the official urbanization rate increased from 18 to 46 percent (All China Data Center 2016) and the economy expanded on average by 8.8 percent annually, resulting in a more than 17-fold increase of gross domestic product (GDP) per capita from just 156 to 2695 current US\$ (The World Bank 2019). However, due to the uneven nature of this development, huge regional disparities emerged (Ravallion and Chen 2007; Wu and Perloff 2005). This makes China a unique case, exhibiting, on the one hand, extreme regional variation in modernization levels and, on the other, a common cultural heritage and identical political institutions. Therefore, China provides an opportunity for disentangling the "tight syndrome of religious/cultural, social, economic, and political characteristics" (Delhey and Newton 2005, p. 13) that complicates cross-national research on social trust.

Research on the impact of modernization on social trust has been focused on crossnational evidence (Almakaeva et al. 2018; de Bliek 2013; Delhey et al. 2011; Delhey and Newton 2005; Inglehart and Welzel 2005; Welzel and Delhey 2015). Only a few studies have analyzed regional variation within countries, e.g. the US (Putnam 2007), Germany (Freitag and Traunmüller 2008), Poland (Działek 2014), and Denmark (Sønderskov and Dinesen 2014). Until a few years ago, China had been a blind spot on the map of trust research. Since then, a number of studies have provided insights into the determinants and structure of social trust in this national context (Huhe 2014; Nee et al. 2018; Sasaki 2016; Steinhardt 2012; Sun and Wang 2012; Tao et al. 2014; Zhou and Hu 2013).

In this article, we explore the contextual socio-economic conditions for the formation of social trust in Chinese rural counties (xian), county-level cities (xianji shi) as well as urban districts $(q u)$ (referred to hereafter as county-level units or counties). Previous research typically focused on trust "in most people", as the most frequently used survey question is phrased. However, this measure of social trust is difficult to interpret in the Chinese context 
(Delhey et al. 2011; Steinhardt 2012; Zhou and Hu 2013). We examine two specific forms of trust-general trust in out-groups and particular trust in in-groups-since modernization might affect them differently. We also cover trust in family, which, however, we find to be largely invariant across regions. We combine the individual-level evidence with economic, fiscal, and population statistics to explore different dimensions of modernization at the county-level, and we analyze the data with hierarchical regression models.

The article is structured as follows: the next section introduces the concept of social trust and its main types. ${ }^{1}$ We then discuss the pessimistic and optimistic modernization narratives and their application to the case of China. This is followed by an introduction of our data and methodology, our results, and several robustness checks. We conclude with a summary and a discussion of our main findings.

\section{Social Trust: Definitions and Distinctions}

Social trust is of interest to social scientists because it serves both as a social glue and lubricant (Phillips 2006). Political scientists praise it as a pre-requisite for a flourishing democracy (Inglehart 1997; Putnam 1993), sociologists as an integrative force for modern societies (Giddens 1990; Simmel 1950), and economists as an ingredient for economic growth (Fukuyama 1995).

Social trust is a risky "bet on the future contingent actions of others" (Sztompka 1999, p. 25). It can be defined as the belief that others will not, at worst, knowingly or willingly do you harm, and will, at best, act in your interests (Delhey and Newton 2003). If we trust, we place a bet on the reasonableness, honesty, and benevolence of others. Scholars commonly separate particular from general trust (Sztompka 1999, Chapter 3). Particular trust is the "thick" trust in people we know personally, and with whom we often have a lot in common, such as family members, friends, or neighbors. General trust, by contrast, is the "thin" trust in unfamiliar people who are often unlike us-broader categories of people and strangers. It is widely accepted that general trust is especially important for the functioning of modern society, while particular trust is more functional in traditional settings (Sasaki 2016; Seligman 2001).

There is a scholarly discussion on the extent to which particular and general trust are empirically related. Some scholars conceptualize the two trust types as being influenced by an underlying propensity to trust and thus expect particular and general trust not to differ much in magnitude and determinants (Rosenberg 1957). Others postulate that particular trust forms a basis on which general trust emerges (Uslaner 2002). Two insights provide strong support for the latter position. First, individuals' decision to regard others as generally (un)trustworthy is based on their experiences with particular people (Freitag and Traunmüller 2009; Glanville and Paxton 2007; Nee et al. 2018). Second, individuals around the globe have substantially more trust in particular others (in-groups) than in general others (out-groups). Whereas it is quite a common pattern for individuals to score higher on particular trust than on general trust, the reverse combination is exceedingly rare (Welzel and Delhey 2015).

\footnotetext{
${ }^{1}$ If not further specified, the terms trust and social trust are used interchangeably and refer to all types of trust in other people.
} 
There is another discussion on the extent to which levels of trust are fixed or malleable. It is argued that people learn trust from early socialization (Uslaner 2002) or cultural heritage (Nunn and Wantchekon 2011; Uslaner 2008), leading to a great deal of stability in adult social trust levels. On the other hand, great improvements in trust levels have been recorded in Germany and Italy after WW2 - a period of democratization and rapid economic growth-(Inglehart 1997), and in Denmark since the 1980s (Sønderskov and Dinesen 2014). In the US, a substantial decline in social trust has been recorded since the 1970s (Putnam 1995), parallel to rising income inequality (Uslaner 2002). These observations prove that trust levels of large groups can change, be it via changing conditions in formative years or via adult responses to large-scale social transformations. Arguably, socio-economic modernization pertains to the conditions that shape trust.

\section{Modernization and Social Trust: Pessimistic and Optimistic Theories}

\subsection{The Pessimistic Account: Modernization as Structural Disruption}

Carving out its disruptive character, the pessimistic view of modernization has an esteemed pedigree. Tönnies (1957) saw the pre-modern Gemeinschaft as more cohesive and trustful than the modern Gesellschaft. Huntington (1973) highlighted the disruptive effects of modernization on political stability and social cohesion. Wirth's influential theory of urbanism as a way of life (1938) spelled out the pessimists' ideas in detail. Wirth claimed that the scale, density, and heterogeneity of modern (urban) life fundamentally alters the character of social relations-largely, to the negative. Modernity is expected to give rise to a number of personal and societal dysfunctions, which make trust of any form unlikely. The mobility and anonymity of modern urban life substitutes secondary contacts for primary ones, resulting in "the weakening of bonds of kinship, and the declining social significance of the family, the disappearance of the neighborhood, and the undermining of the traditional basis of social solidarity" (Wirth 1938, pp. 20-21; see also Huntington 1973, p. 37). These are challenging conditions, especially for maintaining high levels of particular trust. Wirth further identified a spirit of competition and mutual exploitation among modern urbanites, which should also complicate general trust. Contemporary communitarian theorists such as Putnam echo these views. In the US, he notes that "residents of small towns and rural areas are more altruistic, honest, and trusting than other Americans" (Putnam 2000, p. 205), as rural areas are less affected by the disadvantages of modernization.

Hence, the pessimistic account expects that modernization weakens social trust, as it undermines its structural conditions. In this view, processes such as residential mobility, urbanization, and a detraditionalization of life-arrangements result in less normative coherence, stability, transparency, familiarity, and accountability-factors that have been theorized to be important for the formation of a "trust culture" (Sztompka 1999, Chapter 6). Hereafter, we refer to this dimension of modernization, which centers on the social organization of individual and collective life, as "structural modernization."

\subsection{The Optimistic Account: Modernization as Growing Collective Resources}

A contrasting narrative is provided by scholars who approach modernization from an existential security (Inglehart 1997) or human empowerment (Inglehart and Welzel 2005) point of view. Here, modernization is conceptualized as the socio-economic dimension of 
a larger human development syndrome. More specifically, modernization is defined as the growth of collective resources that enhance people's capabilities to act according to their own liking (Inglehart and Welzel 2005, p. 2 ff.). Its most striking components are increasing existential security and cognitive capacities. Because of economic growth and welfare state expansion, people command more economic resources and experience higher existential security. Moreover, average levels of education rise, so that individuals become cognitively more autonomous.

Consequently, the optimistic account predicts a positive association between modernization and social trust, especially towards out-groups and strangers. The disposability of material resources and other conditions of existential security put the average person in a better position to take the risk of trust and decrease the incentives for breaching it, while rising education levels help diffuse a rational-scientific worldview and self-controlled behavior. In the following, we denote this dimension of modernization, which hinges on enhanced capabilities, as "resource modernization."

Recently, the existential security/human development paradigm developed more detailed expectations about changing mechanisms of trust generation at the individual level (Almakaeva et al. 2018; Welzel and Delhey 2015). One of these expectations concerns the conversion of particular trust into general trust. Trust scholars have argued that higher levels of general trust arise in more modern contexts as people are encouraged to extend a larger share of their trust in particular others to general others, resulting in so-called derivative general trust (Welzel and Delhey 2015).

\subsection{Evidence from Previous Research}

The available evidence on general trust, largely stemming from international comparative research, tends to support the "optimists." In economically advanced countries, the level of "trust in most people" has been found to be higher and its radius larger (Delhey et al. 2011). Other cross-national studies have linked trust in out-groups to levels of human empowerment and thus to a conglomerate of collective resources (Welzel and Delhey 2015). Within-country comparisons in European societies found general trust to be higher in economically prosperous areas (Freitag and Traunmüller 2008) and in more urban and educated regions (Działek 2014, for Poland). A study concerned with urbanization in 34 Eurasian transition countries, however, provides inconclusive evidence. Whereas more modern countries - those with relatively large urban populations - show higher levels of trust, modernizing countries - those with higher growth rates of the urban population-are characterized by lower trust levels (de Bliek 2013).

Seen through the lens of modernization theories, results from previous research on trust in China are mixed. In contrast to the optimistic narrative, Huhe, examining individuals living in rural villages with multi-level methods, reported no effect of village income on particular or on general trust (Huhe 2014). Using variants of the trust in "most people" indicator to elicit general trust, other studies even found the highest levels of trust in rural and less economically developed cities (Steinhardt 2012; Sun and Wang 2012). However, in the Chinese context the "most people" indicator measures to a substantial extent particular, not general, trust (Delhey et al. 2011; Steinhardt 2012; Zhou and $\mathrm{Hu} 2013$ ), and is thus difficult to interpret. Also employing the "most people" measure as well as behavioral trust indicators in rural China, another study revealed a positive effect of village-level inward migration, but negative impacts of village income and outward migration (Tao et al. 2014), which is at odds with both modernization narratives. Two other studies at least indirectly 
support the optimistic narrative: the radius of trust has been found to be significantly wider among urbanites and younger cohorts, particularly for those born after 1978 (Zhou and Hu 2013). Pointing in a similar direction, entrepreneurs who learn to trust their business partners extend this trust to general others (Nee et al. 2018).

\section{The Case of China: Towards Testable Hypotheses}

How do the two main theories and empirical insights relate to the case of China? Consistently, scholars have characterized Chinese society before the establishment of the People's Republic, under state socialism, and at the onset of economic reforms in the late 1970s, as one with high levels of trust in family and close associates, combined with low levels of trust in people who do not belong to these networks (Fei 1992; Fukuyama 1995; Redding 1990; Steinhardt 2012; Tang and Parish 2000; Weber 1968; Wong 1996; Zhou and Hu 2013; Zhu 2012). Since the 1980s, China experienced rapid urbanization, as millions of peasants have moved from farm to factory, into rapidly growing cities (Yan 2010, pp. 497-498). Simultaneously, the work units (danwei) of the socialist urban economy, which arranged work and social interactions around relatively narrow circles of known others, were dismantled (Tang and Parish 2000; Yan 2010, pp. 498-499). This twin-process of structural change "disembedded" (Yan 2010, p. 492) large numbers of people from closeknit rural communities and their urban socialist counterparts (akin to Wirth's account of anomic urbanism). As a result, individuals had to interact with a much-enlarged circle of others, including strangers. Thus, the "traditional mode of social association" (Steinhardt 2012, p. 444), where morality and trust are strongly tied to personal relations, became less functional. This helps to explain why the widespread Chinese perception of a trust crisis bears resemblance to the discussion on structural modernization as disruptive urbanism (China News Service 2020; Zhu 2012).

According to the pessimistic school of thought, trust in particular others in China should thus be alive and well in more rural and less developed areas, but considerably weaker in structurally more modern regions ("structural modernization"). For trust in general others, the impact of structural modernization is less clear as pessimistic theorists have mostly considered trust in known individuals. Yet if the modern condition undermines particular trust, this negative effect should extend to general trust. Thus, from the pessimistic school of thought we infer the following hypotheses:

H1 Particular trust is weaker in regions with a higher degree of structural modernization.

H2 General trust is weaker in regions with a higher degree of structural modernization (as weakened particular trust also undermines general trust).

China's socio-economic progress undoubtedly augmented collective resources, most obviously economic ones. In line with the optimistic school of thought, the increase in prosperity and mass education in the higher developed regions should have increased existential security and cognitive autonomy and therefore led to a higher propensity to trust-especially regarding general trust, the riskier of the two forms of trust. As the cultural base-line of general trust in China is assumed to be low, collective resources could make a difference here. In contrast, trust in people one knows personally is safeguarded by repeated interactions, moral obligations and concerns about one's reputation (Ostrom 
and Ahn 2009), especially in a collectivist cultural context such as China. Hence, particular trust is governed by binding social norms of mutual obligation and reciprocity, which are relatively independent from the higher existential security and cognitive autonomy resource modernization brings about. It is therefore unlikely that levels of trust in known others are systematically associated with regional levels of resource modernization, either positively or negatively. This leads to the following second set of hypotheses, inspired by the modernization optimists:

H3 General trust is stronger in regions with a higher degree of resource modernization.

H4 Particular trust is neither stronger nor weaker in regions with a higher degree of resource modernization.

Beyond affecting levels of social trust directly, modernization might also change the mechanisms of the generation of general trust at an individual level, as mentioned above. Evidence suggests that a necessary condition for the derivative extension of trust from people one knows to strangers and out-groups is that individuals have positive experiences with strangers (Freitag and Traunmüller 2009, p. 796; Glanville and Paxton 2007). Such experiences are more likely to take place in urban areas (structural modernization) andechoing Nee, Holm and Opper's findings (2018) —in prosperous regions (resource modernization). Hence, both dimensions of modernization may facilitate the extension of particular into general trust:

H5 The individual-level association between particular trust and general trust is stronger in regions which are characterized by a higher degree of structural modernization and resource modernization.

Figure 1 visualizes our two-level research design and the place of the various hypotheses within our conceptual framework.

\section{Data and Methods}

Our individual-level data comes from the World Values Survey (WVS) wave five for China, which is the only wave for which county-level units have been released for analysis. Respondents aged between 18 and 70 were selected through stratified, multi-stage probability proportional to size sampling. The GPS/GIS-assisted area sampling technique used facilitated the inclusion of domestic migrants, which are often missed by traditional area sampling techniques (Landry and Shen 2005). A total of 1991 interviews were conducted between March and May 2007, yielding a response rate of 78.6 percent. Survey respondents were located in 63 county-level units (18 urban districts and 45 rural counties and county-level cities; for a full list, see Table 4 in "Appendix 1").

To estimate the effects of both individual and contextual characteristics on trust, we employ hierarchical regression models, measuring our higher-level predictors at the county level. Our year of measurement for contextual conditions is 2000 , which provides several key indicators of ethnic fractionalization, urban population, internal migration, household structures and education from the national census. For other years before the Chinese WVS survey in 2007, these indicators are either unavailable or of lower quality. We also assume 


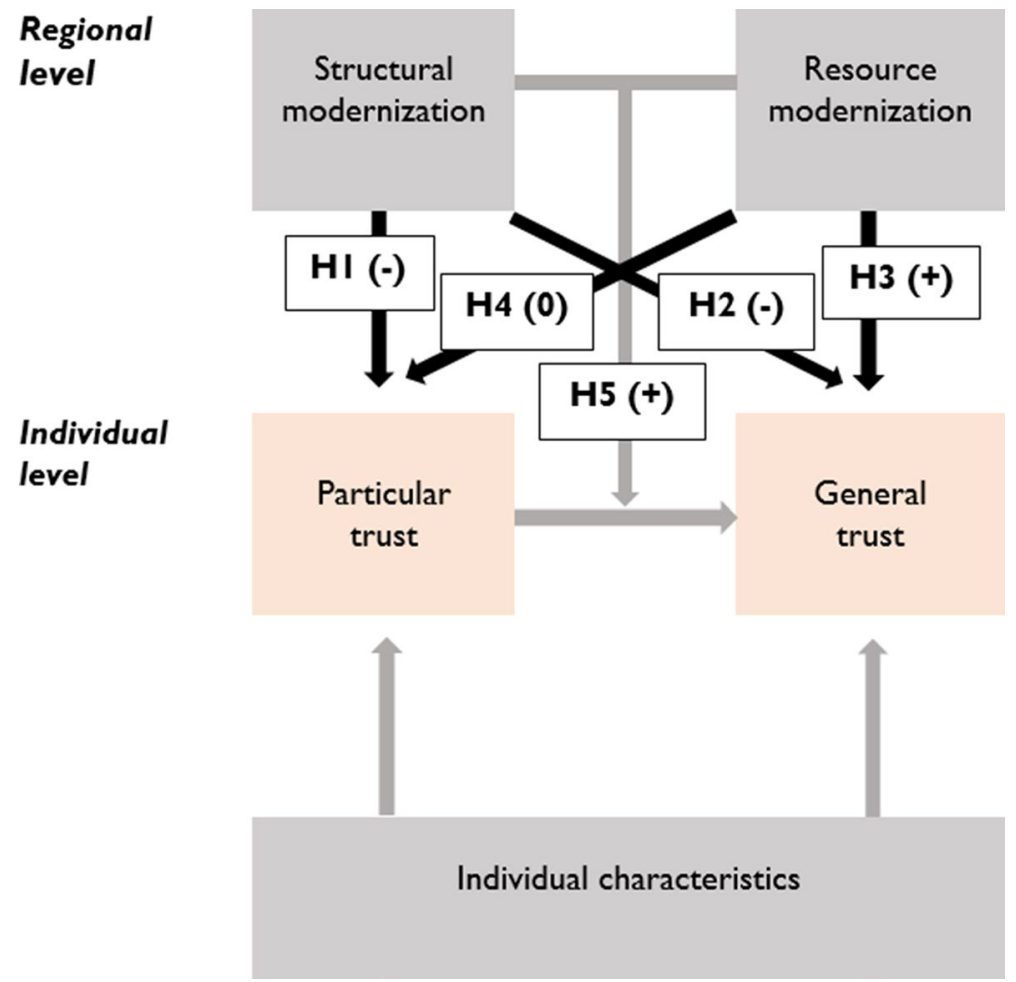

Fig. 1 Conceptual model and hypotheses. Note: (+) Assumes a positive effect, (-) a negative effect, and (0) no effect

that social changes require several years to affect individuals. Despite being correlational in nature, this time-lagged analytical framework increases the plausibility of attributing causality from modernization levels to individual trust (Dragolov et al. 2016, Chapter 2). We excluded data from two county-level units that were established after 2000. Our working sample thus consists of 1927 respondents nested in 61 units, an average of 32 respondents per county. While a larger number of individuals per unit would have been desirable, "in multilevel regression, the relevant sample size for higher-level coefficients and variance components is the number of groups" (Hox 2010, p. 46; see also, Bickel 2007, p. 282). With 61 county-level units we are well above the level-two sample sizes common in crossnational research.

When assigning the contextual information, we assume that rural counties-a unit of administration with a history dating back to antiquity-function as relatively well-integrated social systems (Huang and Deng 2017). Unless they have migrated to cities and are thus included in the urban sample of the survey, rural residents usually live and work in the same county, interact primarily with fellow county residents and receive social services from the county government. This cannot be said of urban districts. Urbanites tend to live and work in different districts and use infrastructure and social services across the city. Thus, the contextual attributes most relevant to trust generation are attributes of the city as a whole rather than a single urban district. We have therefore used city averages instead of district values to measure our modernization indicators. While this marginally reduces 
Table 1 General and particular social trust

\begin{tabular}{lll}
\hline Items & General trust & Particular trust \\
\hline Trust in people one meets for the first time & 0.48 & \\
Trust in people with a different religion & 0.79 & \\
Trust in people with a different nationality & 0.78 & 0.63 \\
Trust in neighbors & & 0.93 \\
Trust in friends and acquaintances & & \\
\hline
\end{tabular}

Note: Depicted values represent factor loading above 0.25 from an obliquely rotated maximum likelihood two-factor analysis. Factor eigenvalues 1.72 and 1.10

variation (on two occasions, two districts from the same city are included in the survey and thus have been assigned the same county-level values), we believe this is a theoretically sounder approach.

\subsection{Social Trust Measures}

We draw on a newly developed WVS battery of trust items. Six items invite respondents to state whether they trust various groups of people "completely, somewhat, not very much, or not at all". Following Delhey et al. (2011), we initially assumed that social trust is composed of the two latent variables of in-group trust, covering trust in "family" (jiaren), "neighbors" (linju), and "friends and acquaintances" (shuren), and out-group trust, comprising trust in people that respondents "meet for the first time" (diyi ci jianmin de ren), "people of another religion" (zongjiao xinyang butong de ren), and "people of another nationality" (qita guoji de ren). ${ }^{2}$

When we ran a confirmatory factor analysis with the Chinese data, however, a two-factor solution did not pass standard goodness-of-fit thresholds. Factor loadings for the trust in family item were particularly weak, suggesting that Chinese perceive trust in family members as conceptually different from trust in other in-groups. Dropping the trust in family item leads to a clear two-factor structure of particular trust (trust in in-groups beyond the family) and general trust (trust in out-groups and strangers), as shown in Table 1.

This leaves us with three trust measures, trust in family (single item, scale 1-4, low to high), and two composite indices of particular trust and general trust. The latter are simple additive indices, re-scaled to a range from 1 to 4 . Two items from the general trust index, trust in "people of another religion" and "people of another nationality", have a substantial number of missing values (40 percent and 38 percent respectively). We suspect, however, these are largely due to the chosen translation of the WVS questionnaire without inducing systematic bias, in particular regarding regional modernization levels. ${ }^{3}$ To verify this assumption, we ran hierarchical regressions with our complete set of controls and

\footnotetext{
${ }^{2}$ On the use of these items from the World Values Survey in China, see also Churchill and Mishra (2017).

3 "People of another nationality" has been rendered as qita guoji de ren, which is a very formal translation. Preferable here would have been the term "foreigner" waiguo ren. Moreover, "religion" has been rendered as zongjiao xinyang. This term connotes "institutionalized religiosity," which is exceptionally low in China and may not fully capture the much more widespread "diffused religiosity" (Tang 2014) of ancestor worship, geomancy, or fortune telling. Some respondents may thus have found it difficult to provide a spontaneous response.
} 
modernization measures (introduced in the following two sections) with the extent of missing values on the general trust index as the dependent variable (coded 0-3). Apart from significant negative impacts of individual associational involvement and life satisfaction, there is no discernable pattern. Most importantly, there is no effect of our modernization measures (results not shown). We, therefore, conduct our main analysis with the composite general trust index, which has been validated cross-nationally (Delhey et al. 2011). Moreover, in our robustness checks we report results from imputed data and the trust in strangers item, which has fewer missing values (6 percent). These results are very similar to our main findings for general trust.

\subsection{Modernization Measures}

In line with the different accounts of modernization delineated above, we distinguish between structural modernization and resource modernization as two key dimensions of the modernization syndrome.

The structural dimension of modernization is comprised of residential mobility, urbanization, and familial detraditionalization, which are all measured at the county-level with census data (All China Data Center 2016). ${ }^{4}$ Residential mobility, urbanization and familial detraditionalization are classical topics of structural modernization (Inkeles 1993; Goode 1963). We measure residential mobility as the percentage of residents with a household registration outside of the location (domestic migrants), plus the percentage of residents with a household registration in another province (thus double-weighting migrants from other provinces). Our measure of urbanization seeks to tap the "de facto" gradual differences in the settlement structure which bring about the changes to patterns of social interaction, rather than the "de jure" official designation of an area as urban or rural (we explore this "de jure" alternative in our robustness checks). We measure urbanization with the percentage of urban population, which has been counted in a novel and "by far the most realistic" (Shen 2006, p. 93) fashion in the 2000 census. ${ }^{5}$ We operationalize familial detraditionalization as the average number of generations per household, computed from census statistics (we inverted it, so that higher values represent fewer generations per household and thus higher detraditionalization). Cohabitation with more than two generations of family is an expression of Chinese traditional family-centered social norms (Fukuyama 1995, p. 174; Jackson and Liu 2017, p. 3). While cohabitation has not disappeared, families have grown smaller, as "separation has become a common and accepted feature of contemporary Chinese family life" (Jackson and Liu 2017, p. 3) and one-person households are on the rise, particularly in cities (Wang 2014). We summarized the three indicators-after standardization - into an unweighted additive structural modernization index (Cronbach's alpha $=0.82$ ).

We examine the resource-dimension of modernization through state welfare, mass education and economic prosperity at the county-level. State welfare expenses are widely seen as an indicator of collective existential security (Pettersen 1995). We measure these as the

\footnotetext{
${ }^{4}$ For the variation of all modernization indicators, please refer to Table 5 in "Appendix 2".

5 All individuals residing in an area defined (by the census) as urban for more than half a year were counted as urban population, independent of their household registration. Districts were defined as urban if they had a density of above 1500 persons per $\mathrm{km}^{2}$. In lower density urban districts and non-urban administrative units, areas were defined as urban if they were administered as streets (jiedao) or were the site of a major local government. For details see Shen (2006, pp. 92-93).
} 
county-level annual per-capita expenses on social security and education, based on fiscal statistics (University Service Center for China Studies, CUHK 2011). Mass education and prosperity are two collective endowments explicitly considered in the Human Development Theory (Inglehart 1997; Inglehart and Welzel 2005). For mass education levels, we focus on tertiary education, as university education is regarded as particularly important by human empowerment scholars (Welzel 2013, Chapter 3). Our indicator is the regional percentage of citizens with an undergraduate university degree or higher based on census data (All China Data Center 2016). We gauge regional economic prosperity by the size of regional GDP per capita provided by the Chinese National Bureau of Statistics (NBS) (All China Data Center 2016). ${ }^{6}$ Again we summarized the three indicators-after standardization-into an unweighted additive resource modernization index (Cronbach's alpha $=0.77$ ).

It should be noted that our distinction between the two facets of modernization is theoretical, inspired by the two modernization schools. Empirically, the two indices are positively correlated $(r=0.82)$. For this reason, and since it is advisable to keep the number of estimated fixed effects as small as possible (Bickel 2007, p. 282), we test the modernization indices mostly separately.

\subsection{Control Variables}

We control for factors known to influence trust, all of which have been examined in their own bodies of literature. At the individual level, this includes a post-material value orientation (e.g. Inglehart 1997; Inglehart and Welzel 2005; Welzel 2013), measured as the standard 4-item post-materialism index; associational involvement (Churchill and Mishra 2017; Paxton 2007; Putnam 1993), operationalized as an additive index of individual group membership and activism. ${ }^{7}$ We control for institutional confidence, an additive index of trust in the police and the courts. The literature regards these two institutions to be at the core of the institutional foundation of trust (Freitag and Bühlmann 2009, p. 1544; Rothstein and Stolle 2008, p. 446). We further include the respondents' stance towards inequality, captured as inequality tolerance (for the same solution, see Huhe 2014). We consider life satisfaction through an additive index of life and financial satisfaction (Delhey and Newton 2003). We also control for education (in years), gender, and age (in years). At the county-level we consider ethnic diversity (e.g. Putnam 2007; Ziller 2015) measured by a fractionalization index (Fearon 2003), which we calculated from the population ratios of the five largest ethnic groups per county reported in the census (All China Data Center 2016). Table 5 in "Appendix 2" provides detailed information on all variables used. All county-level predictors with right-skewed distributions have been log-transformed.

\footnotetext{
6 There is much speculation about problems with Chinese GDP data. While evidence for upward manipulation at times of political turnover has indeed been found, no systematic differences in over-reporting across localities were detected (Wallace 2016). Hence, we assume that such problems do not substantially affect the relative differences across regions.

7 The index does not include a variable asking for membership/activism in political organizations, which in the Chinese case covers primarily the Communist Party. Excluding or including political organizations in the index does not alter the findings reported below. As a stand-alone variable, political organization involvement is not a significant predictor for general or particular trust.
} 


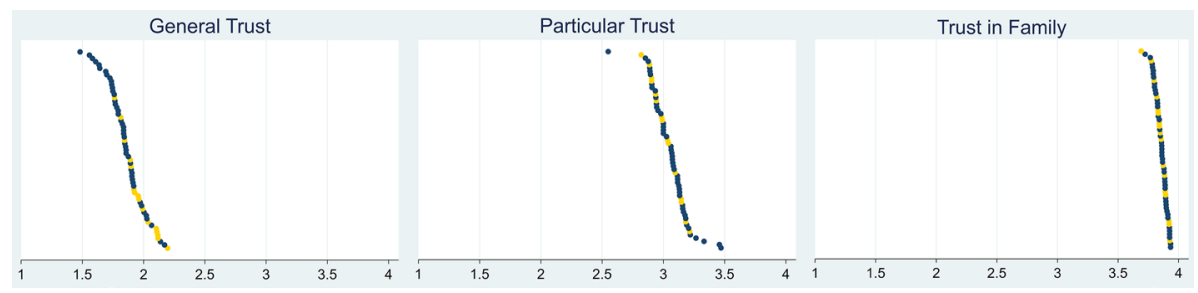

Fig. 2 Random intercepts across county-level units. Note: Level-2 units officially designated as rural are represented by dark-colored markers, urban district counterparts by light-colored markers

\section{Results}

\subsection{Descriptive Analysis: The Regional Variation of Social Trust}

Figure 2 displays estimated county intercepts in random effects ANOVAs with the three types of trust as dependent variables. General trust has a population mean of 1.89 and estimated county intercepts (excluding one outlier) are 0.64 points apart (1.56-2.20). As expected, particular trust is substantially higher, with a population mean of 3.07 and estimated county intercepts (excluding three outliers) that deviate by 0.52 points $(2.82-3.33) .{ }^{8}$ Finally, trust in family has the highest population mean of 3.86 , but intercepts (excluding two outliers) lie merely 0.17 points apart (3.76-3.93).

\subsubsection{The Regional Distribution of General Trust}

Regarding general trust, the position of county-level units that are officially designated as rural counties and county-level cities (represented by dark-colored markers in Fig. 2), and urban districts (white-colored markers) provides initial support for the optimistic modernization narrative. Urban districts are distinctively concentrated at the lower end of the graph, suggesting that people living in the largely more modernized urban areas have higher levels of trust in out-groups and strangers. Tellingly, Xicheng District, in the heart of Beijing and home to the city's financial center as well as the Zhongnanhai central government compound, ranks highest in terms of general trust. Among the ten counties with the highest general trust, seven are urban. From the twenty counties with the lowest general trust scores, all but one are rural. The lowest trust level is estimated for the rural Shuicheng County, located in the underdeveloped Guizhou Province and officially designated as a poverty-stricken county (People's Net 2014). The intra-class correlation (ICC) for general trust is substantial at 0.13 , suggesting considerable regional differences.

\subsubsection{The Regional Distribution of Particular Trust and Trust in Family}

In the case of particular trust (excluding family members), more urban districts are located at the lower half of the distribution than the upper half. From the twenty counties with the highest scores for particular trust, only four are urban areas. If anything, eyeballing the

\footnotetext{
${ }^{8}$ Numbers do not add up due to rounding.
} 
data suggests a weak but negative association between modernization and particular trust. The ICC is at 0.10, and therefore multi-level analysis is required. Regarding trust in family, more urban districts are situated in the lower half of the ranking, but the distribution is less clear-cut, and the respective ICC is small (0.04). Strong trust in family, it appears, is an almost universal feature across Chinese regions.

In the next step, we estimate hierarchical regression models for general and particular trust. We do not further consider trust in family, as the very low regional variation provides little to be explained.

\subsection{The Contextual Impact of Modernization Levels on Social Trust}

To maximize model parsimony and minimize missing values, we first estimated models with control variables only (see Table 6 in "Appendix 3"). We then excluded non-significant individual-level attitudinal predictors (while keeping all socio-demographic controls). This procedure suggests dropping post-materialism for both types of trust and inequality tolerance for particular trust. Notably, regional ethnic fractionalization has no significant impact on either of the types of trust. We nevertheless keep it in the models as it is the only contextual control variable. We now move on to the core of the analyses-the contextual impact of modernization. Models 1 and 2 (Table 2) estimate the effects of modernization levels on particular trust one at a time.

\subsubsection{Explaining Particular Trust}

Individuals' particular trust is not affected by either structural modernization or the level of resource modernization. This disconfirms Hypothesis 1, which assumed that particular trust is weaker in regions with a higher degree of structural modernization but confirms Hypothesis 4, which posited no relationship with resource modernization. Thus, particular trust is insensitive to levels of modernization and neither the optimists nor the pessimists are supported. Regional ethnic fractionalization has no significant bearing on particular trust either. Moving to individual-level characteristics, men, those more satisfied with life and those with higher confidence in institutions have more trust in particular others. What is notable is the negative effect of associational involvement. Although the effect is not strong, ${ }^{9}$ participating in formal associations is apparently somewhat detrimental for trusting in-groups beyond family and kin.

\subsubsection{Explaining General Trust}

Models 3 to 5 (Table 2) estimate the effects of the modernization indices on general trust. This time, both our structural modernization index and our resource modernization index shape the level of individual trust in a statistically and substantially significant fashion: those living in more developed regions trust generalized others more. These findings strongly support the optimistic paradigm of modernization (and our Hypothesis 3 ) but run counter to the pessimistic paradigm (and Hypothesis 2). Raising the modernization indices from minimum to maximum leads to predicted increases of general trust (on a 1-4 scale)

\footnotetext{
9 Changing associational involvement from minimum to maximum is predicted to decrease particular trust from 3.06 to 2.81 .
} 


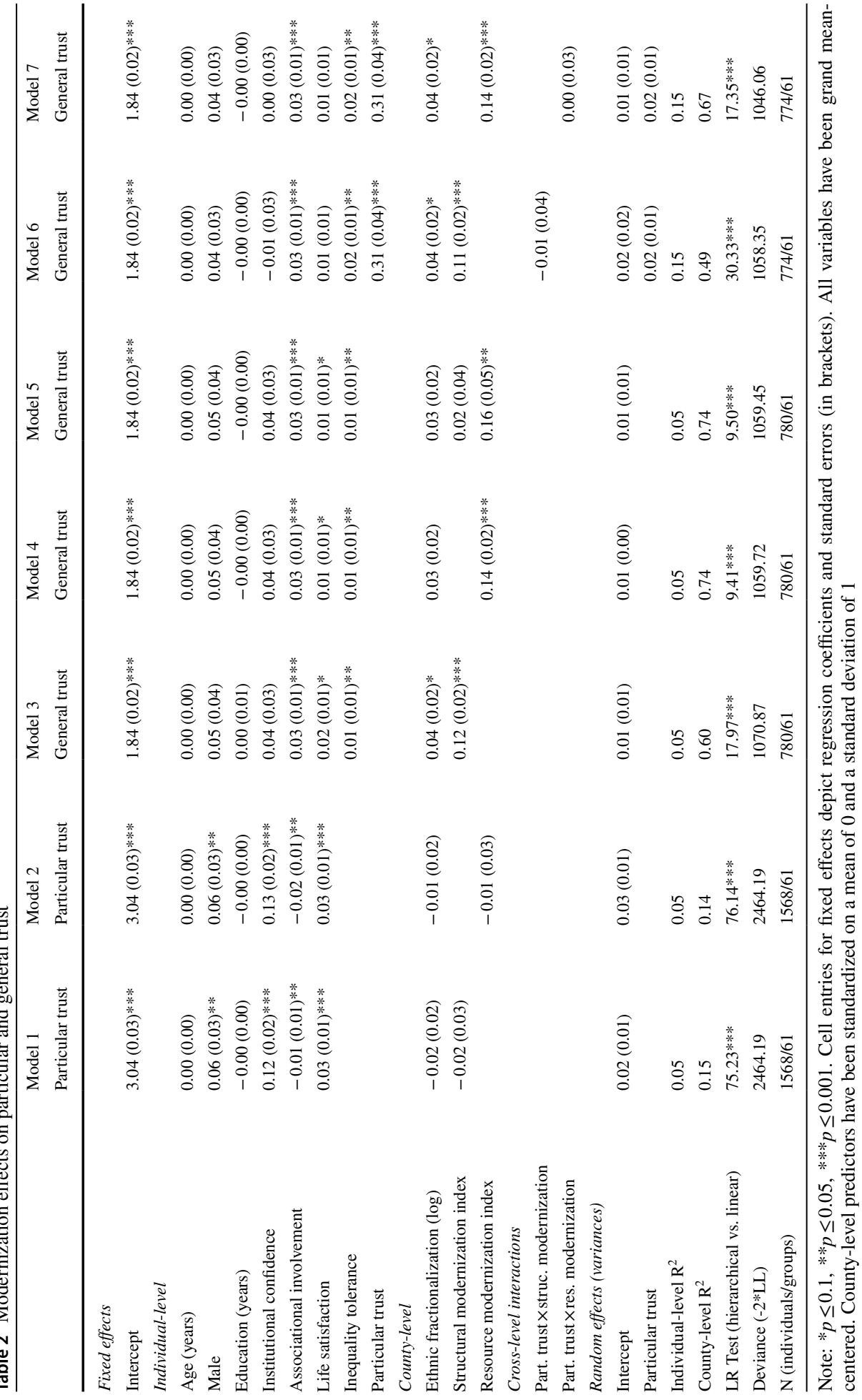


from 1.57 to 2.06 for structural modernization and from 1.64 to 2.29 for resource modernization -in each case a substantial effect. When comparing Models 3 and 4, the explained variance at the county level and model-fit statistics suggest that resource modernization predicts general trust better than structural modernization. This impression is corroborated by Model 5, which includes both indicators at once in a "horse race", resulting in the structural modernization index losing significance, while the resource modernization index remains significant.

Moving to the control variable at the county level, ethnic fractionalization becomes marginally positively significant in Model 3. However, in the models without modernization indices (see Table 6 in "Appendix 3") and in Models 4 and 5, it remains insignificant. This suggests that ethnic fractionalization influences individuals' general trust only in combination with the level of regional modernization, and with structural modernization in particular. The inclusion or exclusion of ethnic fractionalization does not affect the performance of other variables in the models. Three individual characteristics are consistently associated with more trust in general others. Associational involvement and life satisfaction (which is marginally significant) are well-known promoters of general trust. The positive effect of associational involvement stands in contrast to its negative impact on particular trust. Hence, while participating in formal associations may make people less trusting of in-groups, it may expand individuals' trust in out-groups. Notably, the positive effect of inequality tolerance shows that those who are willing to tolerate higher inequality are more trusting. The substantial magnitude of this effect, however, is limited. ${ }^{10}$

\subsection{Cross-level Interactions: Modernization and Trust Conversion}

We now turn to testing for potential cross-level interactions. In Hypothesis 5 we surmised that the derivative extension of particular into general trust is facilitated by regional modernization levels: either because positive interactions with strangers are more likely in structurally modern regions, or because resource-rich settings provide greater existential security. To test these assumptions, we first estimated two additional models with general trust as the dependent variable in which we added particular trust as both a fixed effect and random effect (results not shown). We find a substantially strong and highly significant fixed effect, which indicates that a derivative generation of general trust from particular trust is indeed taking place (as can also be seen in Models 6 and 7 in Table 2). The model with random effects (results not shown) suggests that the slopes for particular trust vary modestly across counties. We therefore estimated two further models in order to examine whether the slopes vary depending on (a) regional levels of structural modernization (Table 2, Model 6) and (b) regional levels of resource modernization (Table 2, Model 7). The interaction terms, however, have no significant effect on general trust, so that Hypothesis 5 has to be rejected. The modest regional variation of the effect of particular trust on general trust can thus not be accounted for by different levels of regional modernization-people in China do not "convert" their particular trust into general trust more easily in urban-resourceful settings. Rather, the larger stock of general trust in these regions appears to be nurtured through the contextual impact of living in a more developed social environment.

\footnotetext{
${ }^{10}$ Shifting inequality tolerance from minimum to maximum in Table 2, Model 5 leads to a predicted increase of general trust from 1.80 to 1.93 .
} 


\section{Robustness Checks}

We have tested the robustness of our findings extensively, both regarding methodological issues and alternative explanations.

\subsection{Methodological Issues}

We first re-estimated our fixed effects models for general trust utilizing the trust in strangers item alone (Table 3). Although effect sizes are smaller, both modernization indices remain highly significant. When included in one model, the two indices cancel each other out (not shown). Hence, although the effects are somewhat weaker, the positive modernization effect we find for the general trust index also surface for trust in strangers als an alternative measure of general trust. Next, we re-estimated fixed effects models for general trust with imputed data. (These and the following robustness checks are not displayed. Results are available upon request). We imputed our data with chained equations and-to account for the hierarchical structure of the data-with Markov chain Monte Carlo estimation (Carpenter et al. 2011; Graham 2009). The findings are highly similar to those reported in Table 2 and lead to exactly the same set of conclusions. Finally, to ensure that our results

Table 3 Modernization effects on trust in strangers

\begin{tabular}{|c|c|c|}
\hline & $\begin{array}{l}\text { Model } 1 \\
\text { Trust strangers }\end{array}$ & $\begin{array}{l}\text { Model } 2 \\
\text { Trust strangers }\end{array}$ \\
\hline \multicolumn{3}{|l|}{ Fixed effects } \\
\hline Intercept & $1.88(0.02)^{* * *}$ & $1.88(0.02)^{* * *}$ \\
\hline \multicolumn{3}{|l|}{ Individual-level } \\
\hline Age & $0.00(0.00)$ & $0.00(0.00)$ \\
\hline Male & $-0.02(0.03)$ & $-0.02(0.03)$ \\
\hline Education (years) & $-0.00(0.00)$ & $-0.00(0.00)$ \\
\hline Institutional confidence & $0.03(0.02)$ & $0.03(0.02)$ \\
\hline Associational involvement & $0.01(0.01)$ & $0.01(0.01)$ \\
\hline Life satisfaction & $0.01(0.01)^{*}$ & $0.01(0.01)^{*}$ \\
\hline Inequality tolerance & $0.01(0.01)$ & $0.02(0.02)$ \\
\hline \multicolumn{3}{|l|}{ County-level } \\
\hline Ethnic fractionalization (log) & $0.02(0.02)$ & $0.02(0.02)$ \\
\hline Structural modernization index & $0.06(0.02)^{* *}$ & \\
\hline Resource modernization index & & $0.06(0.02)^{* *}$ \\
\hline \multicolumn{3}{|l|}{ Random effects (variances) } \\
\hline Intercept & $0.02(0.01)$ & $0.02(0.00)$ \\
\hline Individual-level $\mathrm{R}^{2}$ & 0.01 & 0.01 \\
\hline County-level $\mathrm{R}^{2}$ & 0.18 & 0.14 \\
\hline LR Test (hierarchical vs. linear) & $21.70 * *$ & $24.58 * * *$ \\
\hline Deviance $(-2 * \mathrm{LL})$ & 2735.90 & 2384.73 \\
\hline N (individuals/groups) & $1365 / 61$ & $1365 / 61$ \\
\hline
\end{tabular}

Note: $* p \leq 0.1, * * p \leq 0.05, * * * p \leq 0.001$. Cell entries for fixed effects depict regression coefficients and standard errors (in brackets). All variables have been grand mean-centered. County-level predictors have been standardized on a mean of 0 and a standard deviation of 1 
are not distorted by outliers, we have re-estimated the "strongest" models for general and particular trust, while excluding counties identified as influential cases (based on abovethreshold Cook's D and dfbeta levels). All findings remain highly stable.

\subsection{Alternative Explanations}

We also tested four alternative explanations for the regional general trust patterns we found. First, as residential mobility is part of our index of structural modernization, the regional distribution of general trust may be caused by a composition effect due to the self-selection of more trusting migrants into the more prosperous regions (cf. Tao et al. 2014). Indeed, in the urban part of our sample, those who have lived at their current location of residence for less than ten years (independent of their official household registration) exhibit a slightly higher level of general trust (2.05) than more steady residents (2.00). The inclusion of individual migration experience as a control variable, however, does not undermine the effects of the modernization indicators for general trust. Domestic migration is thus not the mechanism behind the regional pattern of general trust we find.

Second, our measure of urbanization (which is part of the structural modernization index) conceptualizes the phenomenon as a gradual process. In China, however, the legal registration of a household as rural or urban, and the official designation of a place as a rural county or urban district, are also highly consequential. The former is critical for access to social welfare and other resources. The latter affects the urban/rural household registration of the local population, the extent of government investments and the position of the local government in the administrative hierarchy. Hence, urban/rural as a dichotomous administrative distinction may have independent effects on social trust. To resolve this issue, in our analyses on general trust we have included as additional variables both urban household registration (ref.: rural) at the individual level, and urban district (ref.: county/county-level city) at the county-level. Yet, both urban household registration and district are insignificant in our models on general trust and all our key findings remain stable. Hence, it is the "organic", gradual process of urbanization which is consequential for trust formation, not the "de jure" distinction between urban and rural.

Third, it is possible that the effects of modernization we find are, to a large extent, a reflection of China's large rural-urban development gap. To scrutinize this, we have reestimated our models on general trust from Table 2 with the 45 rural level- 2 units only (there are not enough districts for an urban-only estimation). The effect size of structural modernization increases slightly, while the effect size for resource modernization almost doubles. We, therefore, conclude that the optimistic account of modernization is wellsuited to explain general trust differences in China, not only between countryside and city but also within the countryside.

Fourth, what about trust-disrupting events in the past (Nunn and Wantchekon 2011)? The traumatic Chinese Cultural Revolution may well constitute such an event. During its course, people were encouraged to report on others' ideological failings, leading to arbitrary persecutions and, often, death. Research has shown that the intensity of revolutionary upheaval varied substantially across jurisdictions, and was not primarily an urban affair (Walder 2014; Walder and Su 2003). If revolutionary intensity would have been systematically higher in rural, less-modernized regions, a trajectory from the past may thus have an impact on the current geographic variation of social trust. To test whether this is the case, 
we made use of the county-level "China Political Events Dataset, 1966-1971," compiled by Walder, and matched it to our data. ${ }^{11}$ We relied on the reported numbers of victims of persecution, which we divided by the total population at the time so that higher numbers reflect higher persecution intensity. However, in our hierarchical models with modernization indices, regional persecution intensity has no significant effect on either particular or on general trust. There are no reasons to assume that the regional variation of social trust we found originates from the geography of historical trauma.

\section{Discussion and Conclusion}

This study has revisited a long-standing theoretical discussion on the impact of modernization on trust, using the case of China. China features prominently in debates on social trust these days, has undergone an unprecedented process of rapid modernization, and exhibits extreme regional development disparities. Although no time series data are available, this case provides a unique setting to learn more about the association between modernization and trust, as cultural heritages and political institutions are highly similar across China.

Our major findings for the various types of trust are as follows: first, trust in family members is generally high and largely unaffected by regional modernization levels - it is neither undermined, nor strengthened and thus can be considered a deep-rooted cultural trait. This finding dovetails with results from family research, which demonstrate that despite structural changes of the Chinese family, many traditional family values are still very widespread (Hu and Scott 2016). Second, particular trust (particular others beyond family) is also insensitive to levels of modernization. This result disconfirms the pessimistic school of modernization which focused on trust in known others.

Third, our main finding for the level of general trust is straightforwardly supportive of the optimistic narrative: general trust in out-groups and strangers is consistently stronger in more modern regions, especially if modernity is viewed from a resource perspective (confirming the optimists), but also structurally (disconfirming the pessimists). In a transitioning society such as China, existential security is arguably particularly important as a safe foundation on which the risky attitude of trusting out-groups can be built. The fact that structural modernization (when considered alone) is associated with higher general trust may also indicate that putting people in touch with wider circles of others and releasing them from traditional forms of social control may foster the inclination to place trust in those unknown and different from oneself (Inglehart and Welzel 2005, p. 24). Being "disembedded" from traditional and close-knit communities seems to be less disruptive than often assumed, and can in fact be "liberating" (Yan 2010, pp. 492, 497).

Fourth, as elsewhere, we found a considerable positive relationship between particular and general trust (Freitag and Traunmüller 2009; Welzel and Delhey 2015). However, we could not detect an increased conversion of particular trust into general trust in more modern regions. The latter finding is particularly important, as it may point to a general peculiarity of collectivist cultures: the stronger general trust in developed regions does not result from an enhanced generalization of particular trust to out-groups and strangers (Welzel and Delhey 2015), but is nurtured through the contextual effect of residing in more modern social environments.

\footnotetext{
${ }^{11}$ See, https://stanford.app.box.com/s/1p228gewy2pjd3817ksq9kd4d6cz3jy8. We had to exclude eight county-level units because they did not exist at the time.
} 
In terms of ancillary results, the positive effect of life satisfaction on both types of trust is in line with findings in various national contexts (Delhey and Newton 2003). The fact that post-materialism is not effective for predicting social trust in China suggests that in some contexts, material progress in itself fosters general trust, and not only upon changing value orientations, as posited in the Human Development Theory (Inglehart and Welzel 2005). Furthermore, we could not detect that the Chinese Cultural Revolution has left a lasting effect on the stock of social trust.

We have three more unexpected supplementary findings that future research should look into. First, in contrast to research on social trust and inequality (Rothstein and Uslaner 2005; Uslaner 2002), we found that individuals who are more tolerant towards income inequality display a higher level of general trust. Previous studies from China have found no effect of inequality tolerance (Huhe 2014). We surmise the positive effect of inequality tolerance has to do with the fact that Chinese individuals interpret differences between incomes "as much more due to merit, and less due to an unfair social structure, than do citizens of any other country" and is accompanied by widespread optimism about upward social mobility (Whyte 2010, pp. 85-86, 82). Second, in support of a long line of research on general trust (Churchill and Mishra 2017; Paxton 2007; Putnam 1993), we find positive effects of individual associational involvement on general trust. In contrast, the negative effect of associational involvement on particular trust is unexpected. Perhaps engagement in formal organizations and associations diminishes trust in those connected through informal networks. Third, in contrast to findings elsewhere (Putnam 2007; Ziller 2015), our census-based, high-quality indicator of ethnic fractionalization detected no independent and unambiguous effects on either particular or general trust. Future studies are needed to examine this issue in the Chinese context in greater detail.

We also have to acknowledge a number of limitations. Although we can perceive background culture and political institutions as "constant", our selection of regional control variables has been limited to ethnic fractionalization. In particular, we were not able to control for regional income inequality and civil society development, since these statistics are not available. Moreover, the data we used was designed to be representative for larger geographical sub-regions and China as a whole. Our randomly drawn county samples are relatively small and thus display a relevant sampling error. Future studies would profit from larger regional samples. Finally, our data is cross-sectional, and even our time-lagged approach cannot rule out the possibility that higher levels of general trust in more developed regions have helped their efforts to modernize and to be economically successful.

However, there are good reasons to assume that in the case of China, modernization has shaped trust more than vice versa. First, the literature on trust in Chinese society (Fei 1992; Fukuyama 1995; Weber 1968) and on the role of (kin) networks during the economic takeoff (Redding 1990; Wong 1996) unequivocally suggests that socio-economic modernization came first and originated in a context of low general trust. Second, cohorts born after the beginning of economic reforms in 1978 have a significantly wider, and progressively increasing, radius of trust than older cohorts (Zhou and $\mathrm{Hu} 2013$ ), and younger people are most inclined to help strangers (Yan 2009). Third, comparing trust levels in the most recent WVS 2012 with those in 2007, one finds that general trust has increased by 2.6 percent 
(from 1.88 to 1.93 on the 4-point scale), which remains significant in a pooled regression model with controls (at $p=0.06$ ) (results not shown). This suggests that the ongoing modernization in China has further bolstered trust in strangers and out-groups-and lends credit to our argument that a culture of trust emerges in conducive contextual conditions.

What about the diagnosis of a trust crisis in China, our point of departure? Our findings call into question a widespread perception of a modernization-induced social malaise and lend themselves to more optimistic interpretation of anecdotal evidence on which such a perception rests. We agree with Yan that widely discussed incidents of social anomie and mistrust indicate that "moral values and behavioral patterns ... lag behind the fast-changing economy and social structure" (Yan 2009, p. 21) in China. This does not imply that trust has declined. Instead, our findings suggest that rapid modernization has resulted in a situation where the supply of general trust has grown, but the demand for it may have increased even faster. Likewise, media attention to anti-social behavior may not indicate that such incidents have become more frequent, but that "social expectations" (Huang 2016) of trustworthy - and trusting — conduct have risen, and "universalistic notions of love and care" as normative ideals have become more widespread (Yan 2009, p. 21). Rather than assuming a breakdown of trust, as the Chinese discussion on a "trust crisis" often does (China News Service 2020; Zhu 2012), this interpretation suggests that China is already on the path towards a more cooperative and trusting society. A key issue for the coming years will be to continue the expansion of the supply of trust under conditions of a foreseeably slowing pace of structural and resource modernization.

Acknowledgements Open access funding provided by University of Vienna. This research received financial support from the Germany/Hong Kong Joint Research Scheme Grant (57216456; G-CUHK405/15) by the Hong Kong Research Grants Council (RGC) and the German Academic Exchange Service (DAAD). We are grateful to Georgi Dragolov, Tianguang Meng, Leonie Steckermeier and Markus Steinbrecher for extremely helpful comments. We also thank Tianguang Meng for providing us with additional survey data. Earlier versions of this article have been presented at the 2016 European Consortium for Political Research General Conference Prague, Czech Republic; the 2016 Chinese Goverance Innovation Forum, Changchun, China; and the 2017 International Conference on Trust, Chuo University, Japan.

Open Access This article is licensed under a Creative Commons Attribution 4.0 International License, which permits use, sharing, adaptation, distribution and reproduction in any medium or format, as long as you give appropriate credit to the original author(s) and the source, provide a link to the Creative Commons licence, and indicate if changes were made. The images or other third party material in this article are included in the article's Creative Commons licence, unless indicated otherwise in a credit line to the material. If material is not included in the article's Creative Commons licence and your intended use is not permitted by statutory regulation or exceeds the permitted use, you will need to obtain permission directly from the copyright holder. To view a copy of this licence, visit http://creativecommons.org/licenses/by/4.0/.

\section{Appendix 1}


Table 4 List of counties, county-level cities and districts

Sampling unit code, province/municipality, prefecture, Unit type

Number of Cases county/district/county-level city

\begin{tabular}{|c|c|c|}
\hline 1 Liao Ning-Yin Kou-Zhan Qian & District & 46 \\
\hline 2 Liao Ning-Pan Jin-Da Wa & County & 30 \\
\hline 3 Liao Ning-Fu Xin-Zhang Wu & County & 48 \\
\hline 5 Hei Longjiang-Qi Qihar-Ke Shan & County & 66 \\
\hline 7 Hei Longjiang-Mu Danjiang-Dong An & District & 21 \\
\hline 8 Hei Longjiang-Mu Danjiang-Ai Min & District & 37 \\
\hline 9 Shan Xi-Yun Cheng-He Jin & County-level city & 18 \\
\hline 10 Shaan Xi-Wei Nan-Han Cheng & County-level city & 38 \\
\hline 11 Shan Xi-Tai Yuan-Ying Ze & District & 30 \\
\hline 12 Shan Xi-Jin Zhong-Yu Ci & District & 32 \\
\hline 13 He Bei-Zhang Jiakou-Zhang Bei & County & 65 \\
\hline 15 Bei Jing-Feng Tai & District & 40 \\
\hline 16 Bei Jing-Xi Cheng & District & 28 \\
\hline 17 Jiang Su-Xu Zhou-Pei Xian & County & 25 \\
\hline 19 Fu Jian-Zhang Zhou-Long Hai & County-level city & 72 \\
\hline 21 Shan Dong-Lin Yi-Tan Cheng & County & 31 \\
\hline 22 Shan Dong-Lin Yi-Cang Shan & County & 28 \\
\hline 23 Shan Dong-Lin Yi-Yi Nan* & County & 61 \\
\hline 25 Shan Dong-Ri Zhao-Lai Shan & District & 25 \\
\hline 26 Shan Dong-Ri Zhao-Dong Gang & District & 28 \\
\hline 27 Shan Dong-Qing Dao-Ping Du & County-level city & 56 \\
\hline 29 Shan Dong-Qing Dao-Shi Bei & District & 20 \\
\hline 30 Shan Dong-Qing Dao-Ji Mo & County-level city & 17 \\
\hline 31 Zhe Jiang-Tai Zhou-Lu Qiao & District & 48 \\
\hline 32 Zhe Jiang-Tai Zhou-San Men & County & 44 \\
\hline 33 Shang Hai-Nan Hui & District & 28 \\
\hline 34 Shang Hai-Yang Pu & District & 35 \\
\hline 35 Hai Nan-Hai Kou-Mei Lan* & District & 39 \\
\hline 36 Guang Dong-Zhan Jiang-Xu Wen & County & 31 \\
\hline 37 Guang Dong-Yun Fu-Luo Ding & County-level city & 41 \\
\hline $41 \mathrm{Hu}$ Nan-Heng Yang-Heng Dong & County & 14 \\
\hline 42 Hu Nan-Zhu Zhou-You & County & 16 \\
\hline 43 Guang Dong-He Yuan-Zi Jin & County & 49 \\
\hline 47 Hu Bei-Jing Men-Zhong Xiang & County-level city & 31 \\
\hline 49 Hu Bei-Xiao Gan-Xiao Nan & District & 65 \\
\hline 51 He Nan-Zhu Madian-Ping Yu & County & 25 \\
\hline 52 He Nan-Zhu Madian-Shang Cai & County & 36 \\
\hline 53 He Nan-Zhou Kou-Tai Kang & County & 44 \\
\hline 57 An Hui-Fu Yang-Ying Shang & County & 27 \\
\hline 58 An Hui-Bo Zhou-Li Xin & County & 26 \\
\hline 59 An Hui-Chu Zhou-Ding Yuan & County & 26 \\
\hline 60 An Hui-Huai Nan-Pan Ji & District & 32 \\
\hline 61 Xin Jiang-Ba Yinguole-Ku Erlei (Korla) & County-level city & 50 \\
\hline 65 Shaan Xi-Yan An-Zi Chang & County & 18 \\
\hline
\end{tabular}


Table 4 (continued)

Sampling unit code, province/municipality, prefecture, Unit type Number of Cases county/district/county-level city

\begin{tabular}{llr}
\hline 66 Shaan Xi-Yu Lin-Zi Zhou & County & 7 \\
69 Yun Nan-Hong He Zhou-Lu Xi & County & 37 \\
71 Gui Zhou-Liu Panshui-Shui Cheng & County & 10 \\
72 Yun Nan-Qu Jing-Xuan Wei & County-level city & 10 \\
73 Guang Xi-Bai Se-Longlin & County & 32 \\
74 Gui Zhou-Qian Xinan-Ce Heng & County & 38 \\
75 Guang Xi-Bai Se-Ling Yun & County & 23 \\
77 Gui Zhou-Qian Nan-Du Yun & County-level city & 22 \\
79 Guang Xi-Liu Zhou-Yu Feng & District & 26 \\
80 Guang Xi-Liu Zhou-Liu Bei & District & 18 \\
81 Guang Dong-Qing Yuan-Lian Zhou & County-level city & 11 \\
82 Hu Nan-Chen Zhou-Lin Wu & County & 23 \\
83 Hu Bei-Yi Chang-Wu Feng & County & 11 \\
84 Hu Bei-Yi Chang-Chang Yang & County & 37 \\
85 Jiang Xi-Gan Zhou-Hui Chang & County & 28 \\
87 Niang Xi-Gan Zhou-Yu Du & County & 1991 \\
89 Yun Nan-Da Li-Yang Bi & County & 25 \\
To Yun Nan-Da Li-Wei Shan & County & 11 \\
\hline
\end{tabular}

*Excluded in the analysis due to the units' non-existence at the time of county-level data collection

\section{Appendix 2}

Table 5 Variables and measurement

\begin{tabular}{|c|c|c|c|}
\hline Variable & Measurement & $\begin{array}{l}\text { Mean } \\
(\mathrm{SD})\end{array}$ & $\begin{array}{l}\text { Percent } \\
\text { missing }\end{array}$ \\
\hline \multicolumn{4}{|l|}{ Individual level } \\
\hline General trust & $\begin{array}{l}\text { Additive index of trust in "people you meet for the first time" } \\
\text { (diyi ci jianmin de ren), "people of another religion" (yu nin } \\
\text { zongjiao xinyang butong de ren), "people of another nation- } \\
\text { ality" ( qita guoji de ren) ascending from } 1 \text { to } 4 \text { (V128-130). } \\
\text { Cronbach's alpha }=0.74\end{array}$ & $1.89(0.54)$ & 48.62 \\
\hline Particular trust & $\begin{array}{l}\text { Additive index of trust in "neighbors" (linju) and "friends } \\
\text { and acquaintances" (shuren) ascending from } 1 \text { to } 4 \text { (V126, } \\
\text { V127). Cronbach's alpha }=0.70\end{array}$ & $3.07(0.56)$ & 4.05 \\
\hline Trust in strangers & $\begin{array}{l}\text { Trust "people you meet for the first time" (diyi ci jianmin de } \\
\text { ren) ascending from } 1 \text { to } 4 \text { (V128) }\end{array}$ & $1.91(0.61)$ & 6.02 \\
\hline Trust in family & Trust in "family" (jiaren) (V125) & $3.86(0.39)$ & 1.04 \\
\hline Age & In years (V237) & $\begin{array}{l}44.73 \\
(13.30)\end{array}$ & 0.00 \\
\hline Gender & Male (1), Female (0) (V235) & $0.46(0.50)$ & 0.00 \\
\hline Education & In years (V238a) & $6.29(4.43)$ & 0.47 \\
\hline
\end{tabular}


Table 5 (continued)

\begin{tabular}{|c|c|c|c|}
\hline Variable & Measurement & $\begin{array}{l}\text { Mean } \\
(\mathrm{SD})\end{array}$ & $\begin{array}{l}\text { Percent } \\
\text { missing }\end{array}$ \\
\hline $\begin{array}{l}\text { Institutional confi- } \\
\text { dence }\end{array}$ & $\begin{array}{l}\text { Additive index of "level of confidence in" "the police" } \\
\text { (jingcha), the courts" (fayuan) ascending from } 1 \text { to } 4 \text { (V136, } \\
\text { V137). Cronbach's alpha }=0.85\end{array}$ & $3.00(0.67)$ & 9.19 \\
\hline $\begin{array}{l}\text { Associational } \\
\text { involvement }\end{array}$ & $\begin{array}{l}\text { Additive index ranging from } 0 \text { to } 27 \text { of organizational mem- } \\
\text { bership in church or religious, sports or leisure, educational } \\
\text { or artistic, union, environmental, professional, human rights } \\
\text { or charity, consumer organization. Non-members, members, } \\
\text { and active members have the values } 0,1 \text { and } 2 \text { respectively } \\
\text { (V24, V25, V26, V27, V29, V30, V31, V32). Cronbach's } \\
\text { alpha }=0.85\end{array}$ & $1.38(2.80)$ & 1.97 \\
\hline Life satisfaction & $\begin{array}{l}\text { Additive index of "how satisfied are your with your life these } \\
\text { days"/“how satisfied are you with the financial situation } \\
\text { of your household?" (V22, V68) from } 1 \text { to } 10 . \text { Cronbach's } \\
\text { alpha }=0.74\end{array}$ & $6.34(2.22)$ & 4.88 \\
\hline $\begin{array}{l}\text { Inequality toler- } \\
\text { ance }\end{array}$ & $\begin{array}{l}\text { "Incomes should be made more equal", "we need larger } \\
\text { income differences as incentives for hard work" from } 1 \text { to } \\
10 \text { (V116) }\end{array}$ & $5.81(3.10)$ & 16.81 \\
\hline Post-materialism & $\begin{array}{l}\text { Inglehart's (1977) index based on answers to an item asking } \\
\text { for "the most important aims of this country" (V69, V70) } \\
\text { coded as materialist (1), mixed (2), post-materialist (3) }\end{array}$ & $1.56(0.58)$ & 25.79 \\
\hline $\begin{array}{l}\text { Urban-household } \\
\text { registration }\end{array}$ & $\begin{array}{l}\text { Based on question regarding the official household registra- } \\
\text { tion (vpx5). Urban (1), rural (0) }\end{array}$ & $0.23(0.42)$ & 1.56 \\
\hline \multicolumn{4}{|l|}{ County-level } \\
\hline $\begin{array}{l}\text { Ethnic fractionali- } \\
\text { zation }\end{array}$ & $\begin{array}{l}\text { Fearon's (2003) ethnic fractionalization index based on } \\
\text { county-level units' five largest ethnicities in } 2000 \text { census. } \\
\text { On average they make up } 99.78 \text { percent of the total county } \\
\text { populations (All China Data Center 2016) }\end{array}$ & $0.11(0.18)$ & 0 \\
\hline $\begin{array}{l}\text { Residential mobil- } \\
\text { ity }\end{array}$ & $\begin{array}{l}\text { Percentage of residents with household registration in another } \\
\text { province from } 2000 \text { census (All China Data Center 2016) }\end{array}$ & $\begin{array}{l}15.12 \\
(16.67)\end{array}$ & 0 \\
\hline Urbanization & $\begin{array}{l}\text { Percentage of urban population from } 2000 \text { census (All China } \\
\text { Data Center 2016). On the definition and measurement of } \\
\text { urban population in the } 2000 \text { census see Shen (2006) }\end{array}$ & $\begin{array}{l}37.52 \\
(28.12)\end{array}$ & 0 \\
\hline $\begin{array}{l}\text { Familial detradi- } \\
\text { tionalization }\end{array}$ & $\begin{array}{l}\text { Mean generations in one household from } 2000 \text { census, reverse } \\
\text { coded (All China Data Center 2016) }\end{array}$ & $0.27(0.14)$ & 0 \\
\hline $\begin{array}{l}\text { Structural mod- } \\
\text { ernization index }\end{array}$ & $\begin{array}{l}\text { (standardized residential mobility }+ \text { standardized urbaniza- } \\
\text { tion }+ \text { standardized detraditionalization)/3. Cronbach's } \\
\text { alpha }=0.82\end{array}$ & $0.00(1.00)$ & 0 \\
\hline Welfare & $\begin{array}{l}\text { Per capita expenses for social security and education based on } \\
\text { fiscal statistics (University Service Center for China Stud- } \\
\text { ies, CUHK 2011) }\end{array}$ & $\begin{array}{l}99.29 \\
(66.42)\end{array}$ & 0 \\
\hline Mass education & $\begin{array}{l}\text { Percentage of citizens over } 6 \text { years with university degree } \\
\text { (bachelor) based on } 2000 \text { census (All China Data Center } \\
\text { 2016) }\end{array}$ & $1.08(1.96)$ & 0 \\
\hline Prosperity & $\begin{array}{l}\text { GDP per capita based on National Bureau of Statics (All } \\
\text { China Data Center 2016) }\end{array}$ & $\begin{array}{l}7983.06 \\
(7336.00)\end{array}$ & 0 \\
\hline $\begin{array}{l}\text { Resource mod- } \\
\text { ernization index }\end{array}$ & $\begin{array}{l}\text { (standardized welfare }+ \text { standardized mass education }+ \text { stand- } \\
\text { ardized prosperity)/3. Cronbach's alpha }=0.77\end{array}$ & $0.00(1.00)$ & 0 \\
\hline
\end{tabular}

Means and standard deviations (except for the modernization indices) refer to values prior to log transformation and centering 


\section{Appendix 3}

Table 6 Selecting control variables

\begin{tabular}{|c|c|c|}
\hline & $\begin{array}{l}\text { Model } 1 \\
\text { General trust }\end{array}$ & $\begin{array}{l}\text { Model } 3 \\
\text { Particular trust }\end{array}$ \\
\hline \multicolumn{3}{|l|}{ Fixed effects } \\
\hline Intercept & $1.85(0.03)^{* * *}$ & $3.06(0.03)^{* * *}$ \\
\hline \multicolumn{3}{|l|}{ Individual-level } \\
\hline Age & $0.00(0.00)$ & $-0.00(0.00)$ \\
\hline Male & $0.03(0.04)$ & $0.09(0.03)^{* *}$ \\
\hline Education (years) & $-0.00(0.01)$ & $-0.00(0.00)$ \\
\hline Institutional confidence & $0.05(0.03)^{*}$ & $0.11(0.02) * * *$ \\
\hline Associational involvement & $0.03(0.01)^{* * *}$ & $-0.02(0.01)^{* *}$ \\
\hline Life satisfaction & $0.03(0.01)^{* *}$ & $0.03(0.01)^{* * *}$ \\
\hline Inequality tolerance & $0.01(0.01)^{*}$ & $-0.01(0.01)$ \\
\hline Mixed (ref.: materialist) & $0.03(0.04)$ & $-0.04(0.03)$ \\
\hline Post-materialist (ref.: materialist) & $0.02(0.09)$ & $0.08(0.08)$ \\
\hline \multicolumn{3}{|l|}{ County-level } \\
\hline Ethnic fractionalization (log) & $0.02(0.03)$ & $-0.01(0.02)$ \\
\hline \multicolumn{3}{|l|}{ Random effects (variances) } \\
\hline Intercept & $0.03(0.01)$ & $0.03(0.01)$ \\
\hline Individual-level $\mathrm{R}^{2}$ & 0.05 & 0.05 \\
\hline County-level $\mathrm{R}^{2}$ & 0.19 & 0.24 \\
\hline LR Test (hierarchical vs. linear) & $39.22 * * *$ & $42.25^{* * *}$ \\
\hline Deviance $(-2 *$ LL $)$ & 962.03 & 1793.49 \\
\hline N (individuals/groups) & $696 / 61$ & $1173 / 61$ \\
\hline
\end{tabular}

$* p \leq 0.1, * * p \leq 0.05, * * * p \leq 0.001$. Cell entries for fixed effects depict unstandardized coefficients and standard errors (in brackets). All variables have been grand mean-centered

\section{References}

All China Data Center. (2016). China data online. http://chinadataonline.org. Accessed 24 August 2016.

Almakaeva, A., Welzel, C., \& Ponarin, E. (2018). Human empowerment and trust in strangers: The multilevel evidence. Social Indicators Research, 139(3), 923-962. https://doi.org/10.1007/s1120 5-017-1724-z.

Bickel, R. (2007). Multilevel analysis for applied research: It's just regression! (1st ed.). New York: The Guilford Press.

Carpenter, J. R., Goldstein, H., \& Kenward, M. G. (2011). REALCOM-IMPUTE software for multilevel multiple imputation with mixed response types. Journal of Statistical Software, 45(5), 1-14.

China News Service. (2020). Sheke yuan baogao xianshi zhongguo shehui xianru xinren weiji [Chinese Academy of Social Science report indicates that Chinese society enters a trust crisis]. Beijing. http:// pkulaw.cn/fulltext_form.aspx?Db=news\&Gid=ddad4eb1c6d84d3bbdfb\&keyword=\&EncodingNa me $=\%$ E6\%BF\%A0\%E7\%94\%B5\%E5\%A7\%B5\%E7\%BA\%B0\%E5\%B6\%89\%E6\%82\%B5?\&Search_ Mode $=$ accurate $\&$ Search_IsTitle $=0$. Accessed 4 Oct 2013.

Churchill, S. A., \& Mishra, V. (2017). Trust, social networks and subjective wellbeing in China. Social Indicators Research, 132(1), 313-339. https://doi.org/10.1007/s11205-015-1220-2.

Dai, X. (2018). Toward a reputation state: The social credit system project of China. SSRN Scholarly Paper, Rochester, NY. https://papers.ssrn.com/abstract=3193577. Accessed 1 May 2019. 
de Bliek, R. (2013). Rapid urbanization. A strike for civil society, or a necessary transition? Research Paper, Erasmus School of Economics. https://repub.eur.nl/pub/77009. Accessed 13 March 2017.

Delhey, J., \& Newton, K. (2003). Who trusts? The origins of social trust in seven nations. European Societies, 5(2), 93-137.

Delhey, J., \& Newton, K. (2005). Predicting cross-national levels of trust: Global pattern or nordic exceptionalism? European Sociological Review, 21(4), 311-327.

Delhey, J., Newton, K., \& Welzel, C. (2011). How general is trust in "most people"? Solving the radius of trust problem. American Sociological Review, 76(5), 786-807. https://doi.org/10.1177/0003122411 420817.

Dragolov, G., Ignácz, Z. S., Lorenz, J., Delhey, J., Boehnke, K., \& Unzicker, K. (2016). Social cohesion in the western world. What holds societies together: Insights from the social cohesion radar. Berlin: Springer.

Działek, J. (2014). Is social capital useful for explaining economic development in Polish regions? Geografiska Annaler: Series B, Human Geography, 96(2), 177-193. https://doi.org/10.1111/geob.12044.

Fearon, J. D. (2003). Ethnic and cultural diversity by country. Journal of Economic Growth, 8(2), 195-222.

Fei, X. (1992). From the soil: The foundations of Chinese society. Berkeley: University of California Press.

Freitag, M., \& Bühlmann, M. (2009). Crafting trust: The role of political institutionsin a comparative perspective. Comparative Political Studies, 42(12), 1537-1566. https://doi.org/10.1177/0010414009 332151.

Freitag, M., \& Traunmüller, R. (2008). Sozialkapitalwelten in Deutschland: Soziale Netzwerke, Vertrauen und Reziprozitätsnormen im subnationalen Vergleich. Zeitschrift für vergleichende Politikwissenschaft, 2(1), 221-256.

Freitag, M., \& Traunmüller, R. (2009). Spheres of trust: An empirical analysis of the foundations of particularised and generalised trust. European Journal of Political Research, 48(6), 782-803.

Fukuyama, F. (1995). Trust: The social virtues and the creation of prosperity. New York: The Free Press.

Giddens, A. (1990). The consequences of modernity. Stanford: Stanford University Press.

Glanville, J. L., \& Paxton, P. (2007). How do we learn to trust? A confirmatory tetrad analysis of the sources of generalized trust. Social Psychology Quarterly, 70(3), 230-242. https://doi.org/10.1177/01902 7250707000303.

Goode, W. J. (1963). World revolution and family patterns. Glencoe: Free Press.

Graham, J. W. (2009). Missing data analysis: Making it work in the real world. Annual Review of Psychology, 60(1), 549-576. https://doi.org/10.1146/annurev.psych.58.110405.085530.

Hox, J. J. (2010). Multilevel analysis: Techniques and applications (2nd ed.). New York: Routledge.

$\mathrm{Hu}$, Y., \& Scott, J. (2016). Family and gender values in China: Generational, geographic, and gender differences. Journal of Family Issues, 37(9), 1267-1293. https://doi.org/10.1177/0192513X14528710.

Huang, H. (2016). Personal character or social expectation: A formal analysis of 'suzhi' in China. Journal of Contemporary China. https://doi.org/10.1080/10670564.2016.1186363.

Huang, J., \& Deng, Y. (2017). Jurisdiction scale matters: County size and external political efficacy in china. Political Studies, 65(4), 966-982. https://doi.org/10.1177/0032321717695292.

Huhe, N. (2014). Understanding the multilevel foundation of social trust in rural China: Evidence from the China general social survey. Social Science Quarterly, 95(2), 581-597. https://doi.org/10.1111/ ssqu. 12049.

Huntington, S. P. (1973). Political order in changing societies. New Haven: Yale University Press.

Inglehart, R. (1977). The silent revolution: Changing values and political styles among Western publics. Princeton: Princeton University Press.

Inglehart, R. (1997). Modernization and postmodernization: Cultural, economic, and political change in 43 societies. Princeton: Princeton University Press.

Inglehart, R., \& Welzel, C. (2005). Modernization, cultural change, and democracy: The human development sequence. Cambridge: Cambridge University Press.

Inkeles, A. (1993). Industrialization, modernization and the quality of life. International Journal of Comparative Sociology, 34(1), 1-23. https://doi.org/10.1163/002071593X00283.

Jackson, S., \& Liu, J. (2017). The social context of ageing and intergenerational relationships in Chinese families. The Journal of Chinese Sociology, 4(1), 2. https://doi.org/10.1186/s40711-016-0050-1.

Landry, P. F., \& Shen, M. (2005). Reaching migrants in survey research: The use of the global positioning system to reduce coverage bias in China. Political Analysis, 13(1), 1-22. https://doi.org/10.1093/pan/ mpi001.

Nee, V., Holm, H. J., \& Opper, S. (2018). Learning to trust: From relational exchange to generalized trust in China. Organization Science, 29(5), 969-986. https://doi.org/10.1287/orsc.2018.1213.

Nunn, N., \& Wantchekon, L. (2011). The slave trade and the origins of mistrust in Africa. American Economic Review, 101(7), 3221-3252. https://doi.org/10.1257/aer.101.7.3221. 
Ostrom, E., \& Ahn, T. K. (2009). The meaning of social capital and its link to collective action. Edward Elgar Publishing. https://www.elgaronline.com/view/9781845423230.00008.xml. Accessed 9 July 2019.

Paxton, P. (2007). Association memberships and generalized trust: A multilevel model across 31 countries. Social Forces, 86(1), 47-76. https://doi.org/10.1353/sof.2007.0107.

People's Net. (2014). Zhongguo shou ge fupin ri, 592 ge guojia ji pinkun xian mingdan [China's first poverty alleviation day, a list of 592 state-level poverty-stricken counties] People's Net. http://politics. people.com.cn/n/2014/1017/c1026-25854065.html. Accessed 9 June 2016.

Pettersen, P. A. (1995). The welfare state: The security dimension. In O. Borre \& E. Scarborough (Eds.), The scope of government (pp. 198-233). Oxford: Oxford University Press.

Phillips, D. (2006). Quality of life: Concept, policy and practice. Abingdon: Routledge.

Putnam, R. D. (1993). Making democracy work: Civic traditions in modern Italy. Princeton: Princeton University Press.

Putnam, R. D. (1995). Tuning in, tuning out: The strange disappearance of social capital in America. PS: Political Science \& Politics, 28(4), 664-683. https://doi.org/10.2307/420517.

Putnam, R. D. (2000). Bowling alone: The collapse and revival of American community. New York: Simon $\&$ Schuster.

Putnam, R. D. (2007). E Pluribus Unum: Diversity and community in the twenty-first century the 2006 johan skytte prize lecture. Scandinavian Political Studies, 30(2), 137-174. https://doi.org/10.111 1/j.1467-9477.2007.00176.x.

Ravallion, M., \& Chen, S. (2007). China's (uneven) progress against poverty. Journal of Development Economics, 82(1), 1-42. https://doi.org/10.1016/j.jdeveco.2005.07.003.

Redding, G. S. (1990). The spirit of Chinese capitalism. Berlin: Walter de Gruyter.

Rosenberg, M. (1957). Misanthropy and attitudes toward international affairs. Conflict Resolution, 1(4), 340-345. https://doi.org/10.1177/002200275700100403.

Rothstein, B., \& Stolle, D. (2008). The State and social capital: An institutional theory of generalized trust. Comparative Politics, 40(4), 441-459.

Rothstein, B., \& Uslaner, E. M. (2005). All for all: Equality, corruption, and social trust. World Politics, 58(01), 41-72. https://doi.org/10.1353/wp.2006.0022.

Sasaki, M. (2016). A comparative analysis of trust among megacities: The case of Shanghai, Seoul and Tokyo. Development and Society; Seoul, 45(3), 503-536. http://dx-doi-org.uaccess.univie.ac. at/10.21588/dns/2016.45.3.006.

Seligman, A. B. (2001). Role complexity, risk, and the emergence of trust. Boston University Law Review, 81,619 .

Shen, J. (2006). Estimating urbanization levels in Chinese provinces in 1982-2000. International Statistical Review, 74(1), 89-107. https://doi.org/10.1111/j.1751-5823.2006.tb00163.x.

Simmel, G. (1950). The sociology of Georg Simmel/translated, edited, and with an introd. by Kurt H. Wolff. Glencoe: The Free Press.

Sønderskov, K. M., \& Dinesen, P. T. (2014). Danish exceptionalism: Explaining the unique increase in social trust over the past 30 years. European Sociological Review, 30(6), 782-795. https://doi. org/10.1093/esr/jcu073.

Steinhardt, H. C. (2012). How is high trust in China possible? Comparing the origins of generalized trust in three Chinese societies. Political Studies, 60(2), 434-454. https://doi.org/10.111 1/j.1467-9248.2011.00909.x.

Sun, W., \& Wang, X. (2012). Do government actions affect social trust? Cross-city evidence in China. The Social Science Journal, 49(4), 447-457. https://doi.org/10.1016/j.soscij.2012.10.006.

Sztompka, P. (1999). Trust: A sociological theory. Cambridge: Cambridge University Press.

Tang, W. (2014). The worshipping atheist: Institutional and diffused religiosities in China. China: An International Journal, 12(3), 1-26.

Tang, W., \& Parish, W. L. (2000). Chinese urban life under reform: The changing social contract. Cambridge: Cambridge University Press.

Tao, R., Yang, D. L., Li, M., \& Lu, X. (2014). How does political trust affect social trust? An analysis of survey data from rural China using an instrumental variables approach. International Political Science Review, 35(2), 237-253. https://doi.org/10.1177/0192512113492599.

The World Bank. (2019). World Development Indicators. The World Bank. https://databank.worldbank.org. Accessed 29 January 2019.

Tönnies, F. (1957). Community and society. New York: Harper \& Row.

University Service Center for China Studies, CUHK. (2011). Barometer on China's Development. Barometer on China's Development. http://bocd.usc.cuhk.edu.hk/. Accessed 26 August 2016.

Uslaner, E. M. (2002). The moral foundations of trust. Cambridge: Cambridge University Press. 
Uslaner, E. M. (2008). Where you stand depends upon where your grandparents sat: The inheritability of generalized trust. Public Opinion Quarterly, 72(4), 725-740. https://doi.org/10.1093/poq/nfn058.

Walder, A. G. (2014). Rebellion and repression in China, 1966-1971. Social Science History, 38(3-4), 513539. https://doi.org/10.1017/ssh.2015.23.

Walder, A. G., \& Su, Y. (2003). The cultural revolution in the countryside: Scope, timing and human impact. The China Quarterly, 173, 74-99. https://doi.org/10.1017/S0009443903000068.

Wallace, J. L. (2016). Juking the stats? Authoritarian information problems in China. British Journal of Political Science, 46(01), 11-29. https://doi.org/10.1017/S0007123414000106.

Wang, Y. (2014). An analysis of changes in the Chinese family structure between urban and rural areas: On the basis of the 2010 national census Data. Social Sciences in China, 35(4), 100-116. https://doi. org/10.1080/02529203.2014.968349.

Weber, M. (1968). The religion of China. Confucianism and Taoism. New York: The Free Press.

Welzel, C. (2013). Freedom rising: Human empowerment and the quest for emancipation. Cambridge: Cambridge University Press.

Welzel, C., \& Delhey, J. (2015). Generalizing trust the benign force of emancipation. Journal of CrossCultural Psychology, 46(7), 875-896. https://doi.org/10.1177/0022022115588366.

Whyte, M. (2010). Myth of the social volcano: Perceptions of inequality and distributive injustice in contemporary China. Palo Alto: Stanford University Press.

Wirth, L. (1938). Urbanism as a way of life. Indianapolis: Bobbs-Merrill.

Wong, S. (1996). Chinese entrepreneurs and business trust. In G. G. Hamilton (Ed.), Asian business networks (pp. 13-26). Berlin: Walter de Gruyter.

Wu, X., \& Perloff, J. M. (2005). China's income distribution, 1985-2001. The Review of Economics and Statistics, 87(4), 763-775.

Yan, Y. (2009). The good Samaritan's new trouble: A study of the changing moral landscape in contemporary China1. Social Anthropology, 17(1), 9-24. https://doi.org/10.1111/j.1469-8676.2008.00055.x.

Yan, Y. (2010). The Chinese path to individualization. The British Journal of Sociology, 61(3), 489-512. https://doi.org/10.1111/j.1468-4446.2010.01323.x.

Zhou, Y., \& Hu, A. (2013). The radius of generalized trust in contemporary China. Chinese Sociological Review, 46(2), 63-90. https://doi.org/10.2753/CSA2162-0555460203.

Zhu, H. (2012). Xinren weiji yu zhongguo tiyan [The trust crisis and the Chinese experience]. The Journal of Jiangsu Administration Institute, (5).

Ziller, C. (2015). Ethnic diversity, economic and cultural contexts, and social trust: Cross-sectional and longitudinal evidence from European regions, 2002-2010. Social Forces, 93(3), 1211-1240. https://doi. org/10.1093/sf/sou088.

Publisher's Note Springer Nature remains neutral with regard to jurisdictional claims in published maps and institutional affiliations. 